\title{
Humanized Culture Medium for Clinical Expansion of Human Erythroblasts
}

\author{
Giovanni Migliaccio, ${ }^{*} \dagger$ Massimo Sanchez, $\dagger$ Francesca Masiello, $\uparrow$ Valentina Tirelli, $\uparrow$ \\ Lilian Varricchio,* Carolyn Whitsett,* and Anna Rita Migliaccio* $*$ \\ *Division of Hematology and Oncology, Tisch Cancer Institute, New York, NY, USA \\ $\nmid$ Cell Biology and Neuroscience, Istituto Superiore Sanità, Rome, Italy \\ †Hematology, Oncology and Molecular Medicine, Istituto Superiore Sanità, Rome, Italy
}

\begin{abstract}
Ex vivo-generated erythroblasts represent alternative transfusion products. However, inclusion of bovine components in media used for their growth precludes clinical use, highlighting the importance of developing culture media based on pharmaceutical grade reagents. In addition, because adult blood generates ex vivo lower numbers of erythroblasts than cord blood, cord blood has been proposed as the source of choice for ex vivo erythroblast production. To clarify the potential of adult blood to generate erythroblasts ex vivo, experiments were designed to identify growth factors [stem cell factor (SCF), interleukin-3 (IL-3), erythropoietin (EPO), and/or thrombopoietin (TPO)] and the optimal concentration and addition schedule of hormones (dexamethasone and estradiol) sustaining maximal erythroid amplification from adult blood mononuclear cells (MNC) using media with serum previously defined as human erythroid massive amplification culture $\left(\right.$ HEMA $\left.^{\text {ser }}\right)$. Adult MNC stimulated with SCF and IL-3 in combination with EPO generated a 6-12fold increase in erythroid cells while TPO was ineffective. Dexamethasone and estradiol (both at $10^{-6} \mathrm{M}$ ) exerted partially overlapping but nonredundant functions. Dexamethasone was indispensable in the first 10 days of culture while estradiol was required from day $10 \mathrm{on}$. The growth factor and hormone combinations identified in HEMA $^{\text {ser }}$ were then used to formulate a media composed of dialyzed pharmaceutical grade human albumin, human albumin-lipid liposomes, and iron-saturated recombinant human tranferrin (HEMA ${ }^{\text {def }}$. HEMA $^{\text {def }}$ sustained erythroid amplification as efficiently as HEMA $^{\text {ser }}$ for cord blood MNC and 10-fold higher than HEMA $^{\text {ser }}$ for adult blood MNC. In fact, the numbers of erythroblasts generated in HEMA ${ }^{\text {def }}$ by adult MNC were similar to those generated by cord blood MNC. In conclusion, this study identifies growth factors, hormone combinations, and human protein-based media that allow similar levels of ex vivo erythroid expansion from adult and cord blood MNC, paving the way to evaluate adult blood as a source of ex vivoexpanded erythroblasts for transfusion.
\end{abstract}

Key words: Erythroblasts; Human erythroid massive amplification (HEMA) culture; Growth factors; Human albumin; Transfusion

\section{INTRODUCTION}

Stem cell factor (SCF), in combination with interleukin-3 (IL-3) and erythropoietin (EPO), sustains unilineage erythroid maturation in culture $(34,58)$. The further addition of agonists of the glucocorticoid (dexamethasone, DXM) (54) and estrogen ( $\beta$-estradiol, ES) $(17,27,31,39)$ receptor delays differentiation, allowing the generation of a greater number of erythroblasts (EBs) $\left(\sim 10^{9}-10^{10}\right.$ EBs from $10^{6}$ adult or cord bloodderived $\mathrm{CD} 34^{+}$cells, respectively). On the basis of the number of $\mathrm{CD}^{+} 4^{+}$cells contained in an average cord blood collection, investigators have calculated that one cord blood unit cultured under these conditions may produce ex vivo erythroid cells sufficient for two to three transfusions (i.e., two to three times $2.7 \times 10^{12}$ erythroid cells) (37). To be used as an alternative transfusion product, however, the media used to generate these cells require better definition. In particular, the combination of growth factors, the relative role played by DXM and ES in the expansion process, and the identification of pharmaceutical grade reagents to replace proteins of animal origin in the media, as recommended by the FDA guidance for cell therapy products (16), are areas of intensive investigation $(30,37)$.

The generation of EBs from hematopoietic progenitor

Received July 15, 2009; final acceptance December 17, 2009. Online prepub date: January 6, 2010.

Address correspondence to Anna Rita Migliaccio, Tisch Cancer Institute, Mount Sinai School of Medicine, One Gustave L Levy Place, Box 1079, New York, NY 10029, USA. Tel: (212) 241-6974; Fax: (212) 876-5276; E-mail: annarita.migliaccio@mssm.edu 
cells includes a first commitment phase, usually occurring in the first 4-10 days of culture, which generates erythroid precursors (EPCs). In the second phase of culture, EPCs mature into EBs, which ultimately cease to proliferate and begin to mature. The final number of EBs generated by each hematopoietic progenitor by the end of this process is regulated by the growth factors/ hormones to which the cells are exposed and that control the speed with which they progress along the maturation cascade. The receptors expressed by hematopoietic cells as they mature predict that at least partially different growth factor/hormone combinations may control the speed of differentiation at different stages of the process (24). The generation of EPCs from early progenitor cells, identified in humans by the expression of the CD34 marker (CD34+ cells), is strictly controlled by the combination of SCF and EPO (33). Other growth factors, however, such as GM-CSF, IL-3, thrombopoietin (TPO), insulin-like growth factor-1 (IGF-1), and prostaglandin (PGE) $(29,33)$ may synergize SCF and EPO by increasing the number of progenitor cells recruited in the process and/or the number of EBs generated by each progenitor cell as their presence increases both the number and size of erythroid bursts obtained in culture. These growth factors may therefore increase the number of EPCs generated by CD34+ cells. IL-3 and GM-CSF bind a heterodimeric receptor composed of a common signaling ( $\beta$-chain) and a specific binding ( $\alpha$-chain) subunit encoded by genes closely linked on the pseudoautosomal region of the X-Y chromosomes (24). Because these receptors are coexpressed, the biological activities of IL-3 and GM-CSF are partially redundant (24). By contrast, $\mathrm{Mpl}$, the TPO receptor, is expressed on a large spectrum of hematopoietic cells that includes stem cells and cells expressing the EPO receptor (24), suggesting that TPO, by recruiting stem cells, may generate committed erythroid progenitors more efficiently than EPO. On the basis of these considerations, TPO is included in some growth factor formulations for ex vivo expansion of EBs $(1,12)$.

The generation of high numbers of EBs in liquid culture of human $\mathrm{CD}_{3} 4^{+}$cells requires the presence both of glucorticoids and estrogens $(3,55)$. This discovery was based on the extensively described effect of glucocorticoids and steroids on erythroid differentiation in clinical conditions $(13,19)$, in mouse mutants $(3)$, and in culture models of erythroid differentiation $(4,18,48,52)$. Whether these hormones exert direct or indirect effects on erythroid differentiation and the cell type (immature vs. mature cells) targeted is still unclear. Glucocorticoids (prednisone, hydrocortisone, and its synthetic analogue, DXM) increase the number of erythroid bursts generated in vitro by human mononuclear cells (MNC) (18) and block DMSO-induced differentiation of Friend erythro- leukemia cells (52). Steroids (ES, progesterone, and testosterone) also increase the numbers of erythroid bursts in cultures of human MNC (48). However, these hormones do not affect DMSO-induced differentiation (52), suggesting different modes of action.

Glucocorticoids and estrogens mediate their biological effects by forming a complex with the respective receptors that migrate to the nucleus to bind and activate/repress specific target genes (53). The observation that the genes targeted by glucocorticoids are a subset of those regulated by SCF (25) suggests that these hormones may be primarily effective on SCF-sensitive $\mathrm{CD} 34^{+} / \mathrm{EPC}$ cells. In erythroid cells, the ES receptor forms a complex with the transcription factor GATA1, leading to its inactivation (6). Because maturation of EPCs into EBs is concentration dependent with respect to GATA1 (38), ES may retard transition from EPCs and EBs, retaining EPCs in proliferation longer. In addition, ES may increase the proliferation potential of EPCs by upregulating the levels of telomerase activity in these cells (7). Telomerase controls the elongation of the chromosome telomeres, a structure reduced after each cell cycle that measures the number of divisions that a cell may undergo (22). These results suggest that DXM and ES may, respectively, control amplification of early SCF-sensitive, and late (GATA1 and telomere length limited) erythroid cells.

Ex vivo EB expansion is apparently higher in cultures seeded with $\mathrm{CD} 34^{+}$cells than in those using MNC (30). However, because considerable numbers of CD34 ${ }^{+}$ cells are lost during the purification procedure, MNC cultures generate absolute numbers of EBs much higher than those obtained in cultures of $\mathrm{CD}^{+} 4^{+}$cells (30). Because MNC contain accessory cells, DXM and ES may increase the number of EBs generated in culture seeded with MNC also by activating/repressing, accessory cell populations, possibly at concentrations different from those active on erythroid cells. DXM, in fact, suppresses the proliferation of T cells (5) that release growth factors that inhibit EB proliferation (9). On the other hand, the increase in the number of erythroid bursts observed in cultures stimulated with ES is dependent on the presence of monocytes, which likely release growth factors when stimulated by these hormones (10). The mode of action, direct and/or indirect, and the type of cells, early or late erythroid cells or accessory cells, targeted by DXM and ES determine at which stage of erythroid expansion culture these two hormones must be added to exert their maximal effects.

We have previously identified culture conditions, defined as human erythroid massive amplification (HEMA) culture, that sustain the generation of great numbers $\left(10^{8-10}\right)$ of EBs from MNC of either cord blood or adult blood (31). The media used in HEMA cultures contain 
fetal bovine serum (HEMA ${ }^{\text {ser }}$ ) and are not clinical grade. Serum-derived media replacing FBS with its active components (albumin, iron-saturated tranferrin, and lipids) for the growth of human erythroid bursts were first established in 1987 (32). Although these serum-free formulations are still based on bovine-derived proteins, the development of these media generated information on the requirements of EBs in culture that can be exploited to formulate equivalent media composed of reagents of human origin (HEMA ${ }^{\text {def }}$ ) and to test their efficacy.

\section{MATERIALS AND METHODS}

\section{Human Subjects}

Peripheral blood buffy coat was prepared from normal adult blood donations collected at the blood center of "La Sapienza" University (Rome, Italy). Cord blood was obtained from full-term pregnancies at the time of delivery at the Public Hospital of Pescara (Italy). Specimens were collected and provided for this study according to guidelines established by the relevant institutional ethical committees.

\section{Preparation of Peripheral Blood MNC}

Light density MNCs were separated by gradient centrifugation at $400 \times g$ for $30 \mathrm{~min}$ at room temperature over Ficoll-Hypaque $(\rho<1.077$; Amersham Pharmacia Biotec, Uppsala, Sweden) and cryopreserved in media containing 40\% v/v Iscove-modified Dulbecco's medium (IMDM, Lonza Group Ltd, Basel, Switzerland), $50 \%$ v/v fetal bovine serum (FBS, Sigma-Aldrich, St. Louis, MO, USA), and $10 \% \mathrm{v} / \mathrm{v}$ dimethylsulphoxide (DMSO, Sigma-Aldrich). The samples in cryopreservative media were placed in a Nalgene Cryobox (Thermo Fisher Scientific, Roskilde, Denmark) at $-80^{\circ} \mathrm{C}$ overnight and then stored in liquid nitrogen (35).

\section{Media Used for Ex Vivo Expansion}

$H E M A^{\text {ser }}$ Medium. This medium, described elsewere (31), is composed of IMDM supplemented with FBS $(20 \% \mathrm{v} / \mathrm{v})$, detoxified bovine serum albumin (BSA, 15\% w/v purified fraction V, Sigma-Aldrich, see below), Lglutamine (1 ng/ml, $200 \mathrm{mM}$, Euroclone SPA, Milan, Italy), antibiotics $(10,000 \mathrm{U} / \mathrm{ml}$ penicillin $\mathrm{G}$ sodium, $10,000 \mathrm{U} / \mathrm{ml}$ streptomycin sulfate, and $25 \mu \mathrm{g} / \mathrm{ml}$ fungizone, PSF, Lonza Group Ltd), and $\beta$-mercaptoetanol ( $\beta$ Mpt, $7.5 \times 10^{-5} \mathrm{M}$, Sigma-Aldrich).

$H_{E M A^{\text {def }}}$ Medium. This medium contains the same components of the serum-deprived media described by Migliaccio and Migliaccio (32) except that albumin and other bovine proteins are replaced with human proteins. Briefly, the media is composed of IMDM supplemented with detoxified human serum albumin (HSA, 10\% v/v, see below), $\beta$-Mpt, human iron-saturated transferrin (h-
TRF, Sigma-Aldrich), a mixture of lipids (cholesterol, from egg yolks, Cat. No. C3045, Sigma-Aldrich, and soybean lecithin, Cat. No. P3644, Sigma-Aldrich), and a mixture of five nutrients (MIX5). Iron-saturated hTRF ( $1 \% \mathrm{w} / \mathrm{v}$ final concentration) was prepared dissolving $1 \mathrm{~g}$ of protein in $3.2 \mathrm{ml}$ of $\mathrm{FeCl}_{3}\left(7.9 \times 10^{-3} \mathrm{M}\right.$ in $\mathrm{HCl} 10^{-3} \mathrm{M}$ ) in $11.2 \mathrm{ml}$ of IMDM, $\mathrm{pH} 7.2$. Lipids (3\% $\mathrm{w} / \mathrm{v}$ final concentration) were prepared as liposome solution using HSA instead of BSA as previously described (50). The final cholesterol (dissolved in $0.4 \mathrm{ml}$ of absolute ethanol) and soybean lecithin concentrations are $400 \mu \mathrm{g}$ and $1.2 \mathrm{mg} / \mathrm{ml}$, respectively. MIX5 contains human recombinant insulin, sodium pyruvate, nucleosides, trace elements, and L-glutamine (each one as $100 \times$ ) and was used at $5 \% \mathrm{v} / \mathrm{v}$. Human recombinant insulin (Merck KGaA, Darmstadt, Germany, endotoxin content $<0.25)$ was dissolved with $\mathrm{HCl}(0.1 \mathrm{~N})$ at a concentration of $40 \mathrm{mg} / \mathrm{ml}$ and diluted with IMDM to $1 \mathrm{mg} /$ $\mathrm{ml}$ and $\mathrm{pH}$ adjusted with $\mathrm{NaOH}(0.1 \mathrm{M})$. Sodium pyruvate $\left(10^{-2} \mathrm{M}\right)$ (Cat. No. P5280, Sigma-Aldrich) was dissolved in IMDM. The nucleoside-nucleotide solution (adenosine, cytidine, uridine, guanosine, $2^{\prime}$-deoxyadenosine, $2^{\prime}$-deoxycytidine, $2^{\prime}$-deoxythymidine, $2^{\prime}$-deoxyguanosine, all from Sigma-Aldrich) was prepared by dissolving $1 \mathrm{mg}$ of each of them in $1 \mathrm{ml}$ of IMDM. The trace element solution was prepared by dissolving $\mathrm{MnSO}_{4} \cdot \mathrm{H}_{2} \mathrm{O}\left(10^{-7} \mathrm{M}\right),\left(\mathrm{NH}_{4}\right)_{6} \mathrm{Mo}_{7} \mathrm{O}_{24} \cdot 4 \mathrm{H}_{2} \mathrm{O}\left(10^{-7} \mathrm{M}\right)$, $\mathrm{NH}_{4} \mathrm{VO}_{3}\left(5 \times 10^{-7} \mathrm{M}\right), \quad \mathrm{NiCl}_{2} \cdot 6 \mathrm{H}_{2} \mathrm{O} \quad\left(5 \times 10^{-8} \mathrm{M}\right)$, $\mathrm{SnCl}_{2} \cdot \mathrm{H}_{2} \mathrm{O}\left(5 \times 10^{-8} \mathrm{M}\right)$, and $\mathrm{FeSO}_{4} \cdot \mathrm{nH}_{2} \mathrm{O}\left(4 \times 10^{-6} \mathrm{M}\right)$ in IMDM. Additional lipids used in some experiments included "lipids cholesterol rich" from adult bovine serum (LCR, Cat. No. L4646, Sigma-Aldrich, cholesterol content $9.0-11.0 \mathrm{~g} / \mathrm{L}$ and protein content $15.0-25.0 \mathrm{~g} /$ $\mathrm{L}, \leq 6.0 \mathrm{EU} / \mathrm{mg}$ cholesterol), and Lipomax (1\% v/v, Invitrogen S.R.L., Milan, Italy).

\section{Detoxification of Bovine and Human Serum Albumin}

BSA was deionized according to published methods $(30,50)$. Briefly, $50 \mathrm{~g}$ of BSA was dissolved in $125 \mathrm{ml}$ of tissue culture grade water at $4^{\circ} \mathrm{C}$ without stirring. When solubilized, $20 \mathrm{~g}$ of resin (Cat. No. AG-501-X8, BioRad, Hercules, CA, USA) or equivalent amounts of Amberlite AG mixed resin (Type mB-1, SERVA Electrophoresis $\mathrm{GmbH}$, Heidelberg, Germany) were added to the mixture and maintained overnight at $4{ }^{\circ} \mathrm{C}$ without stirring. The decanted solution was diluted $1: 1$ with $2 \times$ IMDM-PSF without $\mathrm{NaHCO}_{3}$ and the $\mathrm{pH}$ adjusted to 7.3 (final BSA concentration $15 \% \mathrm{w} / \mathrm{v}$ ). Human albumin (25\% HSA, Baxter International Inc., Deerfield, IL, USA) was detoxified using a double dialysis process during which the preparation was first dialyzed overnight $\mathrm{a}+4^{\circ} \mathrm{C}$ against endotoxin-free USP water (1:80 v/ v) and then against an equal volume of IMDM. Both BSA and HSA solutions were sterilized by filtration 
(0.45 $\mu \mathrm{m}$, Millipore, Billerica, MA, USA) and endotoxin contamination excluded with the Lymulus Amebocyte Lysate assay (Lonza Group Ltd) and pretested for their efficacy to sustain the growth of human erythroid bursts in semisolid assay against a standard (Stem Cell Technology, Vancouver, Canada, http://www.stemcell.com). The final solutions were stored at $-20^{\circ} \mathrm{C}$ for 6 months.

\section{Expansion of Human EBs}

For each experiment, $50 \times 10^{6}$ adult MNCs were thawed and washed twice in IMDM plus $1 \%$ BSA or HSA to remove residual DMSO. Cells were kept overnight in IMDM, 5\% FBS, 4\% BSA (or 9\% HSA), $1 \%$ L-glutamine/PSF/ $\beta$-Mpt and supplemented with SCF and IL-3 (1 ng/ml each) at $37^{\circ} \mathrm{C}$ in a fully humidified $5 \% \mathrm{CO}_{2}$ /air atmosphere (Forma Scientific, Marietta, $\mathrm{OH}$, USA). The following day (considered day 0 culture), viable MNCs were counted, washed once with IMDM plus $1 \%$ FBS (or HSA), and seeded at $10^{6}$ cells/ $\mathrm{ml}$ in $\mathrm{HEMA}^{\mathrm{ser}}$ or HEMA ${ }^{\mathrm{def}}$ medium and stimulated with human SCF (SCF, 10 ng/ml, Amgen, Thousand Oaks, CA, USA), human EPO (3 U/ml, Neorecormon, Auckland, New Zeland), and human IL-3 (1 ng/ml, Biosource, San Jose, CA, USA). DXM and ES (both from Sigma-Aldrich) were added at $10^{-6} \mathrm{M}$ final concentration, unless otherwise stated. Selected experiments were performed in the presence of human TPO $(50 \mathrm{ng} / \mathrm{ml}$ of PEG-MGDF, Kirin Brewery, Gunma, Japan). The cells were cultured at $37^{\circ} \mathrm{C}$ in a fully humidified $5 \% \mathrm{CO}_{2}$ /air atmosphere for 17-21 days. During the culture, the cell concentration was monitored on a regular basis and the cultures supplemented with fresh media to maintain the concentration below $10^{6}$ cells $/ \mathrm{ml}$. DXM and ES $(0.5 \%$ $\mathrm{v} / \mathrm{v})$ were freshly added to the culture every $48 \mathrm{~h}$.

\section{Differentiation of Ex Vivo-Generated EBs}

EBs generated in HEMA cultures were induced to mature by an additional 4 days of culture in media containing EPO $(3 \mathrm{U} / \mathrm{ml})$ and recombinant human insulin (10 ng/ml).

\section{Cell Count and Viability Assessment}

Cell numbers and viability were assessed using manual techniques and trypan blue dye exclusion (dilution $1: 1)$ every $48 \mathrm{~h}$.

\section{Morphological Assessment}

Cell morphology was analyzed according to standard criteria on cytocentrifuged (Cytospine3, Shandon, Astmoor, England) smears stained with May-GrünwaldGiemsa. Microscopic evaluations were performed using cytocentrifuged preparations of $3 \times 10^{5}$ cells per sample with a ZEISS AXIOSKOPE light microscope (Carl Zeiss
Inc., Chester, VA, USA) equipped with a Coolsnap Video camera (Roper Scientific, Munich, Germany).

\section{Immunophenotypic Analysis}

Cell antigenic profile was analyzed by flow cytometry. For any sample, $5 \times 10^{5}$ cells were suspended in $\mathrm{Ca}^{2+} \mathrm{Mg}^{2+}$-free phosphate-buffered saline, supplemented with $0.5 \%$ BSA, $2 \mathrm{mM}$ EDTA, $0.01 \% \mathrm{NaN}_{3}$, and labeled with the following anti-human antibodies: isothiocyanate (FITC)-conjugated CD36 (anti-thrombospondin receptor), or isothiocyanate (FITC)-conjugated CD61 (anti-megakaryocytes) and phycoerythrin (PE)-conjugated CD235a (anti-glycophorin A), or appropriate isotype controls (all from Immunotech, Milan, Italy). All the antibodies were incubated for $30 \mathrm{~min}$ in the dark on ice. Propidium iodide was used to exclude dead cells (5 $\mu \mathrm{g} / \mathrm{ml}$, Invitrogen). Stained cells were analyzed with a FACSAria (Becton Dickinson and Company, Franklin Lakes, NJ, USA) and results analyzed using FlowJo software (version 7.2.5, Tree Star Inc., Ashland, OR, USA). Size determinations were obtained by comparing the mean forward scatter of the cells with those expressed by calibration beads $(6-15 \mu \mathrm{m}$ in diameter; Flow Cytometry Size Calibration Kit, Molecular Probes, Eugene, OR, USA), as previously described (47).

\section{Statistical Analysis}

Cell amplifications are presented as fold increase (number of cells at day $X /$ number of cells at day 0 ), unless otherwise stated. Results are the mean \pm SD of multiple experiments. Statistical analysis was performed by paired $t$-test with the Origin 6.1 software for Windows (Microcal Software Inc, Northampton, MA, USA).

\section{RESULTS}

Growth Factor Requirements for Massive Ex Vivo Amplification of Human Adult Erythroblasts

The growth factors necessary for optimal ex vivo EB expansion in the absence of hormones were identified by culturing adult blood MNC for 14 days in HEMA ${ }^{\text {ser }}$ media stimulated with SCF, IL-3, and EPO, alone and in combinations (Fig. 1). The generation of cells in culture was expressed as fold increase (FI), a ratio that underestimates EB expansion because it does not take into account that EPCs are rare among MNCs and that their frequency among progenies obtained with different growth factors may vary.

After 10-14 days of culture, hematopoietic cells were observed in the presence of all the growth factor combinations analyzed. The cells generated in cultures were usually of multiple lineages but predominantly macrophages and lymphocytes, with the exception of cultures stimulated with SCF + EPO and SCF + IL-3 + EPO, in which the cells were mostly EBs at various stages of 

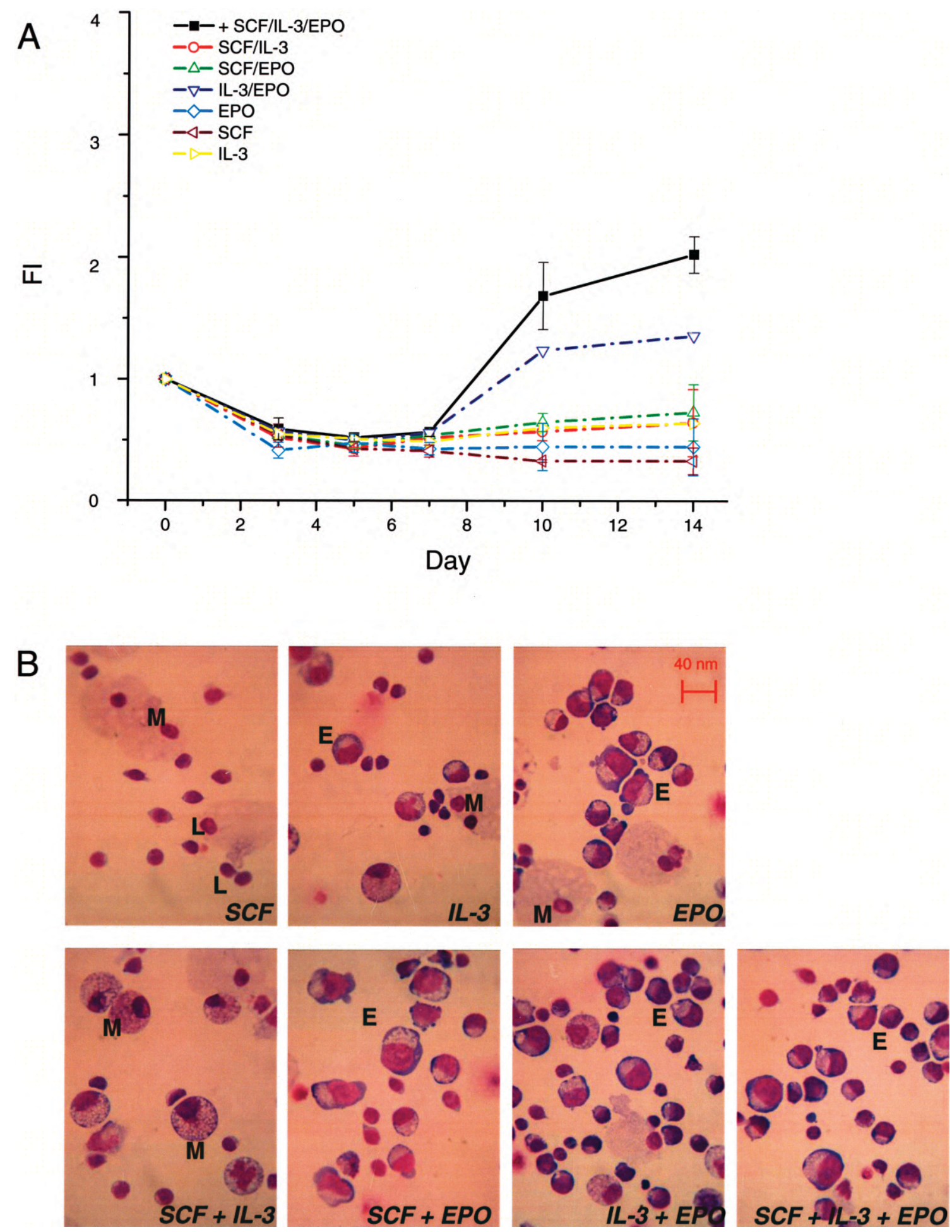

Figure 1. SCF, IL-3, and EPO in combination induce erythroid maturation in vitro. (A) Time course study of the number of cells [presented as fold increase (FI) with respect to day 0] generated in HEMA ${ }^{\text {ser }}$ cultures of adult MNC stimulated with IL-3, SCF, and $\mathrm{EPO}$ alone and in combinations, as indicated. Results are presented as mean \pm SD of three separate experiments, each one with a different donor. (B) May-Grünwald-stained cytospin preparation of cells from day 14 cultures supplemented with the growth factor combinations analyzed in (A), as indicated. M, macrophages; L, lymphocytes; E, erythroblasts. Original magnification 40×. 
maturation (Fig. 1B). The combination that generated the highest, although still modest, numbers of EBs (FI > 2) was SCF + IL-3 + EPO (Fig. 1A) and was therefore chosen to stimulate expansion of EBs in the other experiments.

\section{Dexamethasone and Estradiol Exert Distinctive, but Partially Overlapping, Effects on Ex Vivo Expansion of Human Adult Erythroblasts}

The relative impact of DXM and ES on the expansion of EBs in vitro was assessed by comparing the number of EBs generated in HEMA ${ }^{\text {ser }}$ culture of adult MNC where the concentration of DXM or ES was maintained at $10^{-6} \mathrm{M}$ while varying the concentration of the other hormone within ranges previously reported to be active in vitro $\left(10^{-7}-10^{-5} \mathrm{M}\right)$ over a period of 19 days. Because these cultures were stimulated with SCF + IL-3 + EPO, it is not surprising that almost all of the cells detected from day 7 on were EBs (Fig. 2 and data not shown).

Addition of DXM alone $\left(10^{-6} \mathrm{M}\right)$ increased EB expansion from the twofold increase observed between day 7 and 14 in cultures stimulated with growth factors alone (Fig. 1A) to sixfold (Fig. 2A). Further addition of ES increased the number of EBs generated over time in a concentration-dependent fashion up to a concentration of $10^{-6} \mathrm{M}$ with no further increase. In the presence of DXM alone, maximal numbers of EBs were observed at day 14 while in cultures stimulated with DXM and ES the numbers of EBs increased up to day 17 (Fig. 2A). EBs obtained in the presence of DXM and ES (both $10^{-6}$ M) were more homogenous in terms of maturation stage, and more resistant to physical stress than those obtained with higher DXM concentrations (see the morphology and the density of the cells in the cytospin preparations presented in Fig. 2C). By contrast, ES alone $\left(10^{-6} \mathrm{M}\right)$ did not increase the number of EBs generated in culture above those observed with growth factors alone (Fig. 2B). The further addition of DXM increased the number of EBs generated in those cultures up to a concentration of $10^{-6} \mathrm{M}$, above which the cells no longer increased in number and became fragile to physical stress (Fig. 2B and D).

In conclusion, the concentration of DXM and ES that sustains maximal generation of EBs in HEMA ${ }^{\text {ser }}$ cultures of adult $\mathrm{MNC}$ is $10^{-6} \mathrm{M}$.

The observation that ES alone did not further increased the numbers of EBs generated in culture above that obtained with growth factors suggested that the two hormones may control different stages of the maturation process. To clarify this point, experiments were performed to determine the time at which DXM and ES exerted their maximal effects (Fig. 3). In these experiments, HEMA ${ }^{\text {ser }}$ cultures were divided into two periods: day $0-10$, when the number of cells present in the cul- tures is still below input values and does not include morphologically recognizable EBs, and from day 10 on when morphologically recognizable EBs begin to accumulate. We hypothesized that a hormone whose role would be mainly to enhance commitment and to stimulate accessory cells would be more active in the first 10 days of culture while a hormone that would retard EB maturation would be more effective at later time points. Hence, DXM and ES, alone or in combinations, were added for the first 10 days and then withdrawn from day 10 on (Fig. 3). To take into account the donor variability in the response to hormones, these experiments were repeated with MNCs obtained from 10 separate donors.

In spite of the great variability of results obtained with multiple donors, control experiments confirmed that ES, although ineffective alone in generating high numbers of EBs in culture, did consistently synergize with DXM in generating greater numbers of EBs over time (results in cultures stimulated with DXM alone and DXM + ES are statistically different by paired $t$-test, $p<0.05)$. Retarded addition experiments demonstrated that the presence of DXM was essential in the first 10 days of culture to observe amplification of EBs. Cultures initiated for the first 10 days in the absence of hormones (Fig. 3B) or with ES alone (Fig. 3D) did not generate high numbers of EBs when stimulated with hormones, alone or in combination, at later time points. On the other hand, cultures initiated with DXM + ES generated similar numbers of EBs when stimulated with only one hormone, either ES or DXM, for the last 7 days (Fig. 3C). However, the highest number of EBs were generated in cultures stimulated with DXM alone for the first 10 days and then switched to ES for the last 7 days. In fact, in these cultures, the number of EBs did not reach a plateau at day 14 but continued to increase for the duration of the experiments (day 21) (Fig. 3D).

These results indicate that the presence of DXM is essential for optimal expansion during the first 10 days of culture. Both DXM and ES sustain amplification of EBs from day 10 of culture, although ES is more potent than (and may even be antagonistic to) DXM at these later time points.

\section{Megaloblastic Appearance of Adult Erythroblasts Generated Ex Vivo Under HEMA ${ }^{\text {ser }}$ Conditions}

EBs obtained in cultures stimulated with DXM and ES have a megaloblastic morphology (Fig. 2). Flow cytometry studies were performed to quantify the size of the EBs obtained in these cultures (Fig. 4). Ex vivogenerated EBs from adult MNCs range in size from 30 to $50 \mu \mathrm{m}$ (i.e., a size three times greater than that of the corresponding cells generated in vivo). When EBs were cultured in differentiation media containing only EPO, the size decreased from $40.1 \pm 1.4$ to $28.5 \pm 2.0,21.2 \pm$ 

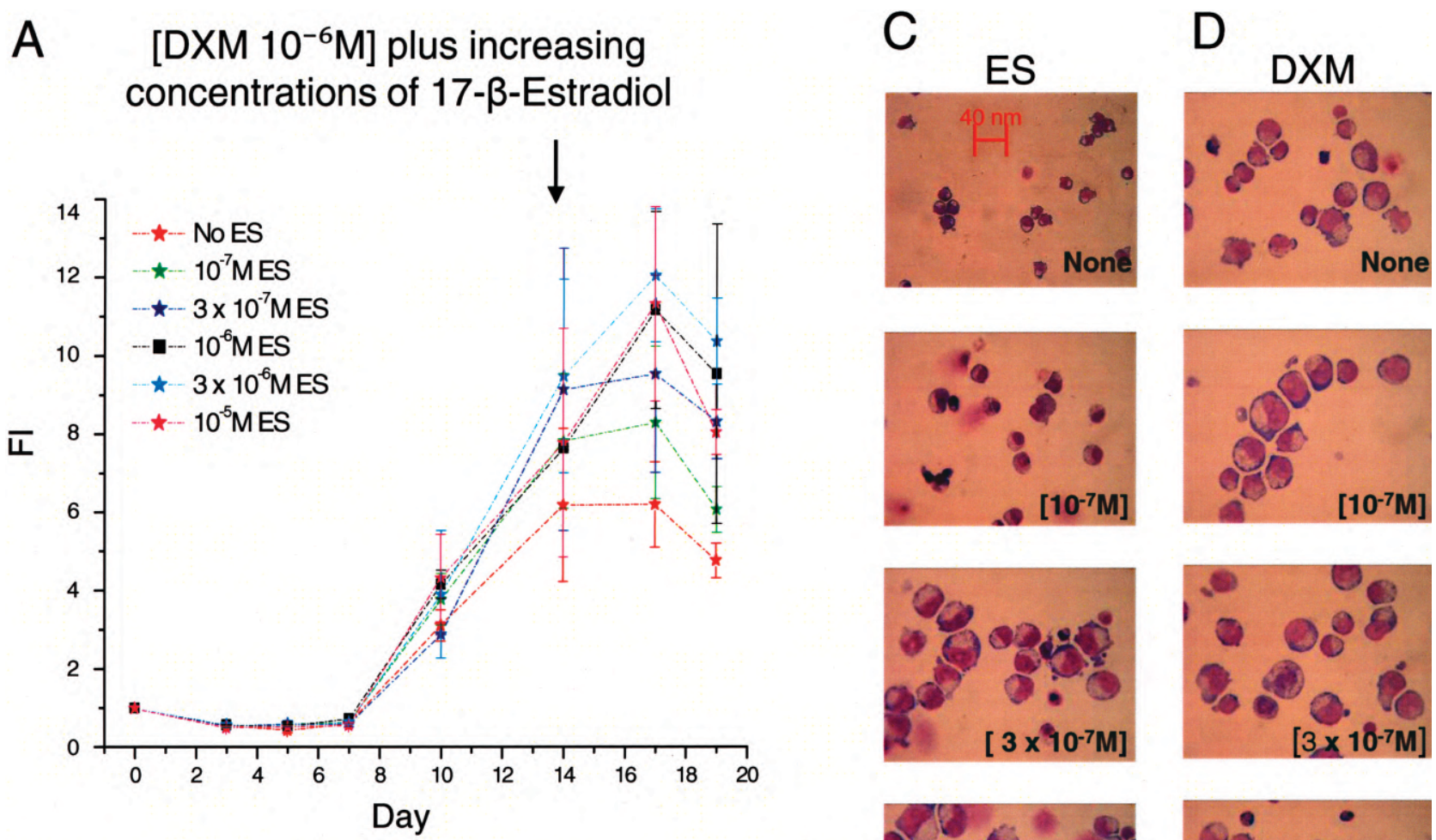

\section{B $\quad\left[E S ~ 10^{-6} \mathrm{M}\right]$ plus increasing concentrations of DXM}
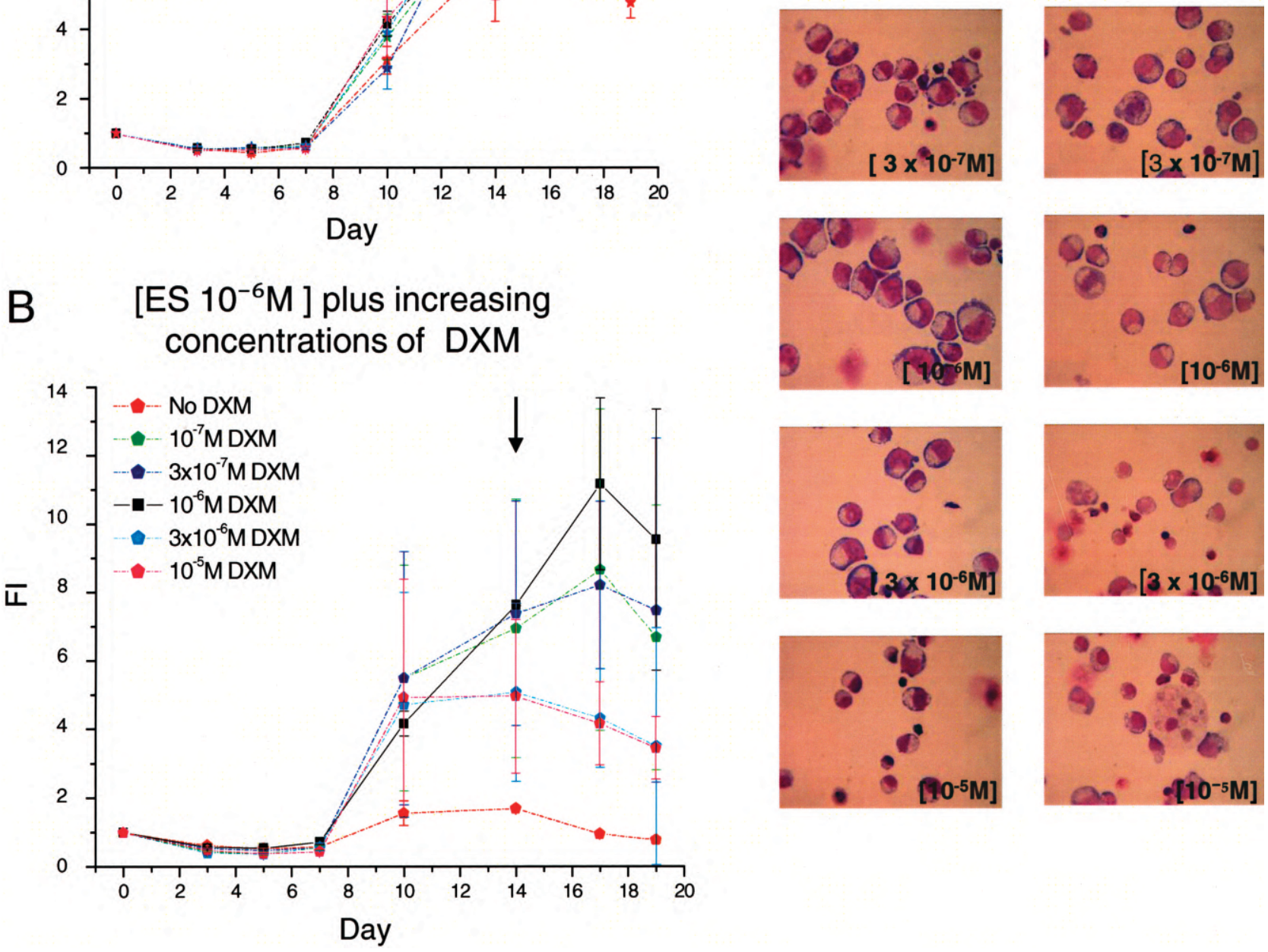

Figure 2. Both dexametasone and estradiol $\left(10^{-6} \mathrm{M}\right)$ are required for massive amplification of erythroid cells in HEMA def cultures. (A, B) Time course study of the number of cells [presented as fold increase (FI) with respect to day 0] generated in HEMA ${ }^{\text {ser }}$ cultures of adult MNC stimulated with either DXM or ES $\left(10^{-6} \mathrm{M}\right.$ each) plus increasing concentrations of either ES (A) or DXM (B), as indicated. The cultures were stimulated with IL-3, SCF, and EPO. In both panels, values obtained with DXM and ES (10-6 M) in combinations are indicated by black squares. Results are presented as mean \pm SD of two experiments each with a different donor. (C, D) May-Grünwald staining of cytospin preparations from representative day 14 cultures stimulated with ES (10 $\left.{ }^{-6} \mathrm{M}\right)$ plus increasing concentrations of DXM (C) and with DXM $\left(10^{-6} \mathrm{M}\right)$ plus increasing concentrations of ES (D), as indicated. Because equivalent cell numbers were spun in all the data points, differences in cell density reflect differences in cell fragility. Original magnification $40 \times$. 

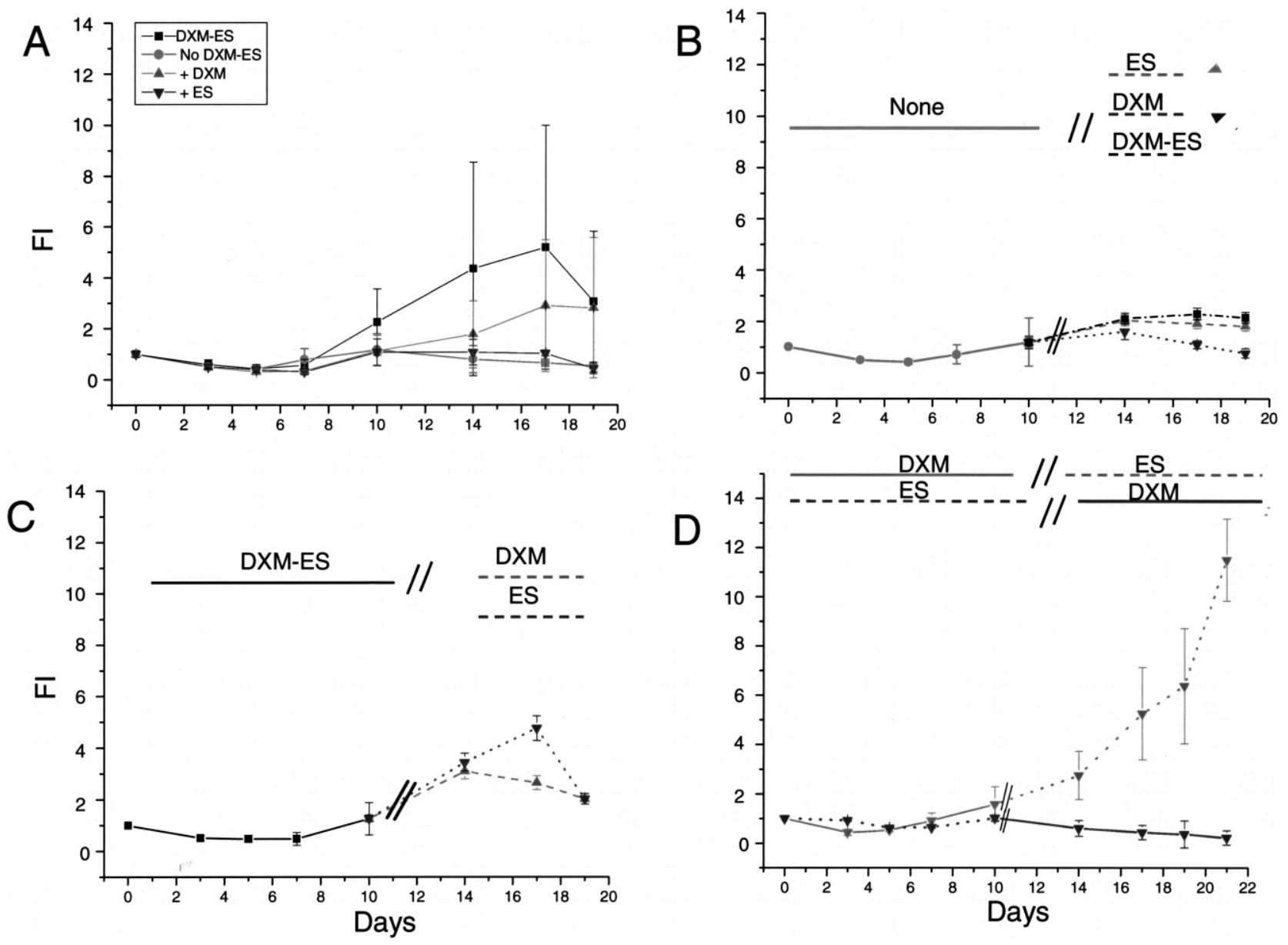

Figure 3. Dexamethasone and estradiol promote ex vivo amplification of erythroid cells by exerting unique roles at different stages of the culture. (A) Time course of the total number of cells [presented as fold increase (FI) with respect to day 0] generated in cultures of adult MNCs stimulated with SCF, IL-3, and EPO, alone or in combination with DXM and/or ES, as indicated. (B, C) Time course of the total number of cells generated in cultures of adult MNCs stimulated for the first 10 days with no hormone (B), with DXM and ES in combination (C), or with either DXM or ES (D) and then switched for the rest of the culture to ES and DXM, alone and in combination (B); DXM and ES alone (C) or DXM and ES (D), as indicated. DXM and ES were used at a concentration of $10^{-6} \mathrm{M}$ and the cultures were also stimulated with SCF, IL-3, and EPO. Results are presented as mean \pm SD of 10 separate experiments each one with a separate donor (A, B, C) and of two separate experiments (D).

0.7 , and $11.6 \pm 0.3 \mu \mathrm{m}$ by 24,48 , and $96 \mathrm{~h}$, respectively (each value is statistically different from that observed in proliferation media, $p<0.01$ in all comparisons). The mature orthochromatic cells observed after 4 days of culture in EPO are still macrocytic (11.6 vs. $8 \mu \mathrm{m}$ of adult normocytic red cells), although smaller than fetal red cells $(12.5 \mu \mathrm{m})(40)$. The size of enucleated red cells obtained from these ex vivo-expanded red cells has not been measured because of their low frequency in maturation cultures without a feeder layer $(17,36)$.

Therefore, the megaloblastic appearance of EBs generated in HEMA culture is reversible when cells mature in EPO, acquiring a size similar to that of cells generated in vivo.
Thrombopoietin Is Ineffective for Ex Vivo Expansion of Human Adult Erythroblasts Under HEMA Conditions

The total number of EBs generated ex vivo may be increased by favoring proliferation of early progenitor cells before commitment to the erythroid lineage becomes irreversible. Because TPO has been reported to increase the number of EBs generated ex vivo from adult $\mathrm{CD} 34^{+}$cells (42), experiments were undertaken to determine whether TPO would increase the numbers of EBs generated under HEMA ${ }^{\text {ser }}$ conditions. In these experiments, the numbers of EBs generated in $\mathrm{HEMA}^{\text {ser }}$ cultures of adult MNCs stimulated with SCF + IL-3 in combination with either EPO or TPO were compared 
(Fig. 5). By contrast to the great numbers of EBs generated in cultures stimulated with SCF + IL-3 + EPO, very few cells were observed in the presence of SCF + IL-3 in combination with TPO (Fig. 5A). In addition, lymphocytes, which represented only $5-10 \%$ of the cells detectable after 13-17 days in cultures stimulated with EPO, were the predominant $(46-60 \%)$ population in the parallel cultures stimulated with TPO (Table 1).

$\mathrm{Mpl}$, the receptor for TPO, has been reported to be expressed on human bipotent megakaryocytic/erythroid progenitor cells (14). It could be argued, therefore, that TPO may have expanded the erythroid progenitors but that these cells failed to mature because of lack of EPO. It is also possible that erythroid cells generated in the presence of SCF + IL-3 + EPO could be induced to grow in the presence of TPO. To test these hypotheses, TPO withdrawal (Fig. 5B) and delayed addition (Fig. 5C) experiments were performed. In the withdrawal experiments, HEMA ${ }^{\text {ser }}$ cultures where stimulated with
$\mathrm{SCF}+\mathrm{IL}-3$ + TPO for 17 days and switched to SCF + IL-3 in combination with either TPO or EPO for 5 additional days. No increase in total cell numbers was observed under either condition (Fig. 5B). In the delayed addition experiments, HEMA $^{\text {ser }}$ cultures were initiated with SCF + IL-3 + EPO for 17 days and then split into cultures stimulated with $\mathrm{SCF}+\mathrm{IL}-3$ in combination with either EPO or TPO for 5 days. A sharp decrease (64\% to $55 \%$ of day 0 ) in total cell number was observed between 17 and 20 days in cultures supplemented with SCF + IL-3 + TPO while the number of EBs observed in those stimulated with SCF + IL-3 + EPO remained almost constant (Fig. 5C). By flow cytometry analyses, the majority of the cells that survived in the presence of TPO in these experiments were erythroid $\left(\mathrm{CD} 36^{+} \mathrm{CD} 235 \mathrm{a}^{+}\right)$whereas those expressing the megakaryocytic marker CD61 were $<2 \%$ in all cases (data not shown).

These results suggest that the presence of the hor-
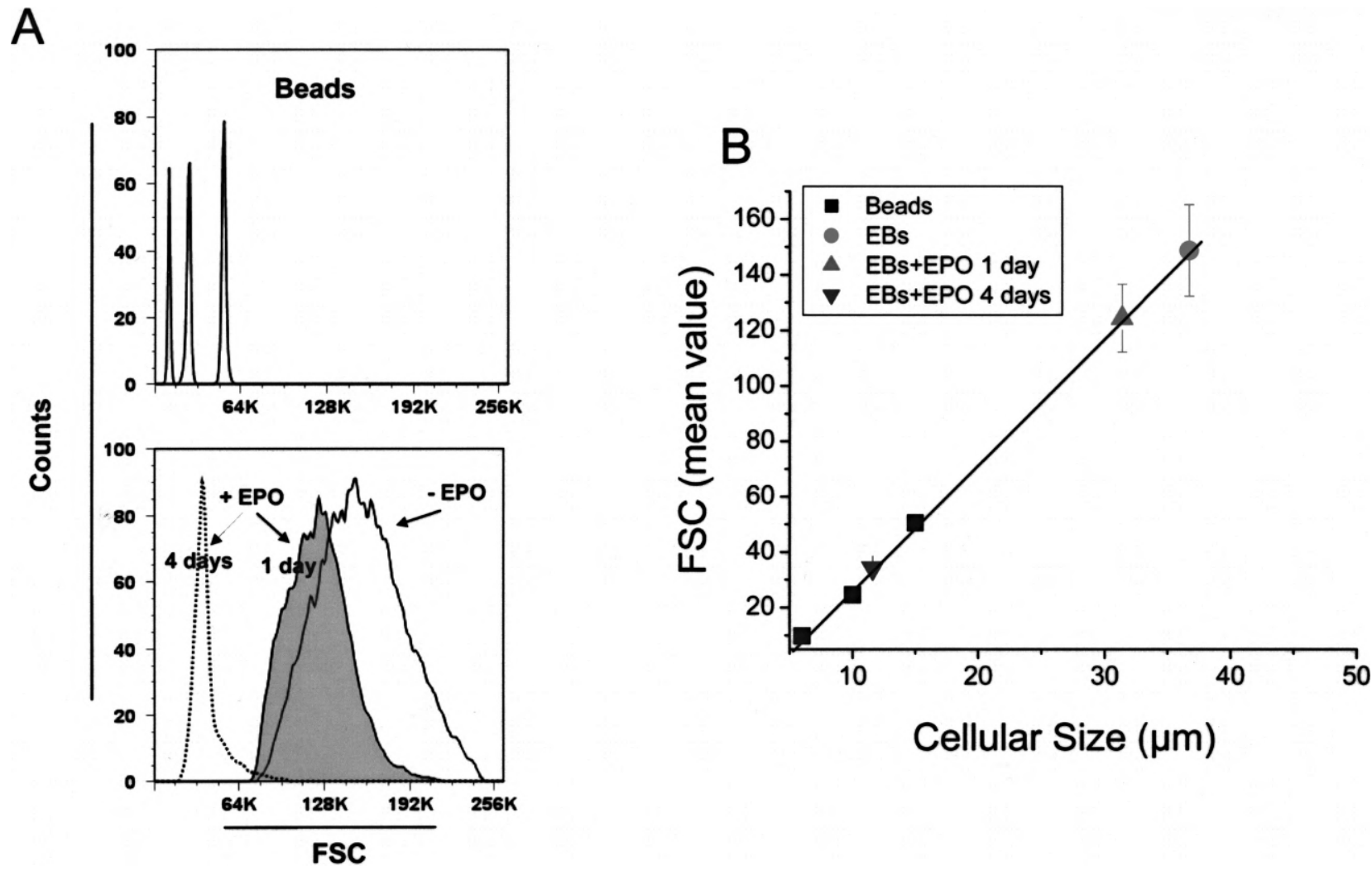

Figure 4. Erythroblasts amplified ex vivo from adult MNC under HEMA ${ }^{\text {def }}$ conditions are megaloblastic and became normal in size when induced to mature by EPO. (A) Comparison of the forward size scatter (FSC) expressed by commercial beads of defined size $(6,10$, and $15 \mu \mathrm{m}$, top panel) and ex vivo-generated erythroblasts before (-EPO) and after (+EPO) being exposed to EPO for 1 or 4 days (bottom panel). (B) Linear regression between the FSC and the size of the calibration beads $(R=0.995)$ and calculation of the average size expressed by ex vivo-expanded erythroblasts (EBs). Results are present as the mean \pm SD of six separate experiments. The differences in size between untreated and 1 or 4 days EPO-treated EBs are statistically significant $(p<0.001)$ by paired $t$-test. 

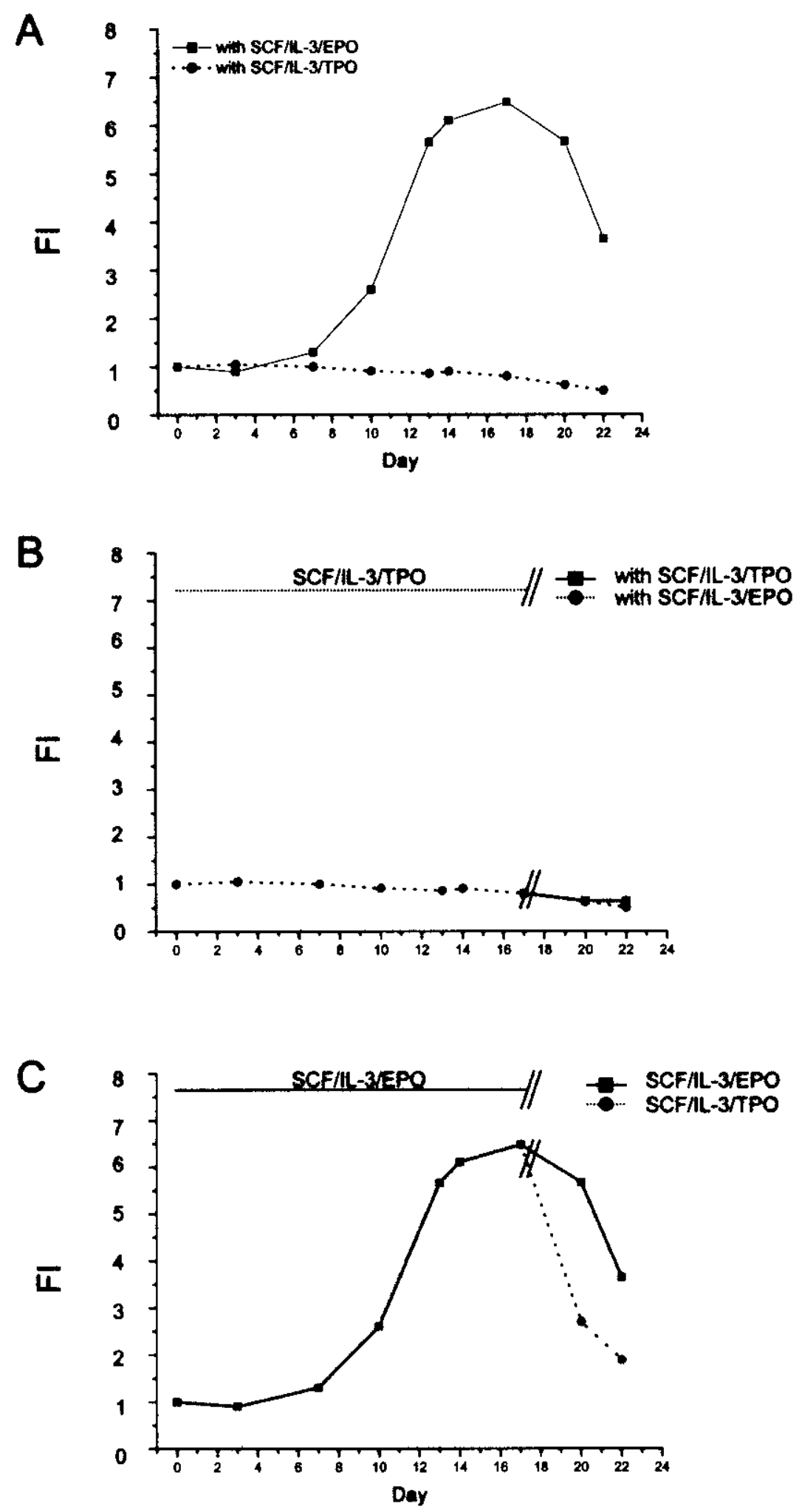

Figure 5. TPO does not sustain generation of erythroblasts from adult MNC under HEMA ${ }^{\text {def }}$ conditions. (A) Total number of cells generated over time (day 22) in cultures stimulated with SCF, IL-3, and EPO or SCF, IL-3, and TPO in the presence of DXM and ES. (B) Effects of removal from (day 15) or (C) addition to (day 15) culture of TPO to the number of cells generated over time in HEMA $^{\text {ser }}$ cultures of adult MNC. Results are representative of those obtained in two separate experiments, each with a different donor. 
Table 1. Frequency of Lymphoid and Erythroid Cells in HEMA ${ }^{\text {ser }}$ Cultures of Adult MNCs Stimulated With SCF and IL-3 in Combination With Either EPO or TPO

\begin{tabular}{llrrrrrr}
\hline & & \multicolumn{5}{c}{ Days in Culture } \\
\cline { 3 - 8 } Growth Factors & Cell Populations* & 3 & 7 & 10 & 13 & 17 & 20 \\
\hline \multirow{2}{*}{ SCF + IL-3 + EPO } & lymphoid cells (\%) & 88 & 48 & 19 & 10 & 5 & 4 \\
& erythroid cells (\%) & 8 & 49 & 77 & 86 & 90 & 87 \\
SCF + IL-3 + TPO & lymphoid cells (\%) & 86 & 73 & 68 & 60 & 46 & 48 \\
& erythroid cells (\%) & 10 & 24 & 29 & 38 & 51 & 48 \\
\hline
\end{tabular}

*By FACS analyses, the cultured cells were divided on the basis of size and CD235a staining into lymphocytoid (small and CD235a ) and erythroid (large and CD235a ${ }^{+}$) cells. The results of a representative experiment are shown.

mones DXM and ES interferes with the ability of erythroid cells to respond to TPO and that maturation along the megakaryocyte pathway under HEMA ${ }^{\text {ser }}$ conditions is minimal.

\section{Development of HEMA ${ }^{\text {def }}$ Media}

Previous attempts to use ex vivo-expanded human cells have identified possible adverse events linked to the use of bovine proteins in culture. Subjects treated with repeated administration of the ex vivo-expanded cells developed an arthus-like reaction to components of the FBS present in the medium used for cell production (46).

Serum-free medium optimized for in vitro differentiation of human erythroid progenitors has been previously established by replacing FBS with its individual active components (albumin, transferrin, lipids, and other additives including vitamins and cofactors) (32). In preliminary experiments, this serum-free medium was capable of supporting ex vivo expansion of EBs from adult and cord blood MNC as well as HEMA ${ }^{\text {ser }}$ (data not shown), identifying the active components of the FBS that had to be replaced with equivalent elements of human origin in the formulation of the HEMA ${ }^{\text {def }}$ medium.

Appropriate lipid and iron delivery represent critical aspects of the development of serum-repleted media. Commercial sources of albumin are contaminated with lipids. In addition, albumin has the property to bind iron in the media and to deliver it to the cells. Therefore, a deficiency of lipids and iron does not limit cell growth under serum-free conditions but albumin-based cell delivery of these compounds may not be sufficient for massive EBs amplification. Lipids can be solubilized in water as liposomes, artificial vesicles whose membrane bilayer is composed of cholesterol and phospholipids that, in the absence of apolipoprotein E, are slowly absorbed by cultured cells by diffusion. The inclusion of albumin in the lipid bilayer stabilizes the liposome struc- ture and favors its adsorption by the cells. HSA-based liposomes can be prepared according to methods published for BSA $(32,50)$, and human recombinant transferrin (h-Trf) is commercially available and can be saturated with iron according to published methods $(32,50)$.

In preliminary experiments, the requirement for efficient lipid and iron delivery systems for ex vivo EBs amplification under HEMA conditions was evaluated by comparing the numbers of EBs generated in BSA-based serum-free cultures supplemented or not with HSAbased liposomes (chol-lecithin) and h-Tfr (Fig. 6). Commercial sources of lipids of bovine origin were included in the analyses, for comparison. Preliminary concentration/response curves and delayed addition experiments conducted with the commercial FBS-derived preparations (Lipomax and LCR) confirmed that lipids, although toxic at high concentrations, improve the numbers (FI = 3 vs. 7 in lipid-repleted and lipid-supplemented cultures, respectively) and the morphology, especially from day 17 on, of EBs generated in serum-deprived medium (Fig. 6A, and data not shown). HSA-based liposomes were as efficient as the commercial lipid preparations in sustaining ex vivo EB expansion in these cultures (Fig. 6A). The further addition of h-Trf did not increase the number (results not shown) but improved the morphology of the EBs generated at day 17 (Fig. 6B, and data not shown), which became similar to that of cells generated in HEMA ${ }^{\text {ser }}$ (compare Fig. 6B and Fig. 2C, D).

Because of its central role in the preparation of the other components of the medium, the most important component to be humanized was albumin. Commercial sources of clinical grade human albumin approved for human use as plasma volume expanders were obtained from Baxter (5\% and 25\% w/v albumin USP). These solutions are prepared from pooled blood donor plasma screened/treated for infectious agents. In preliminary experiments, these human albumin solutions were toxic both in semisolid and liquid culture of primary human 

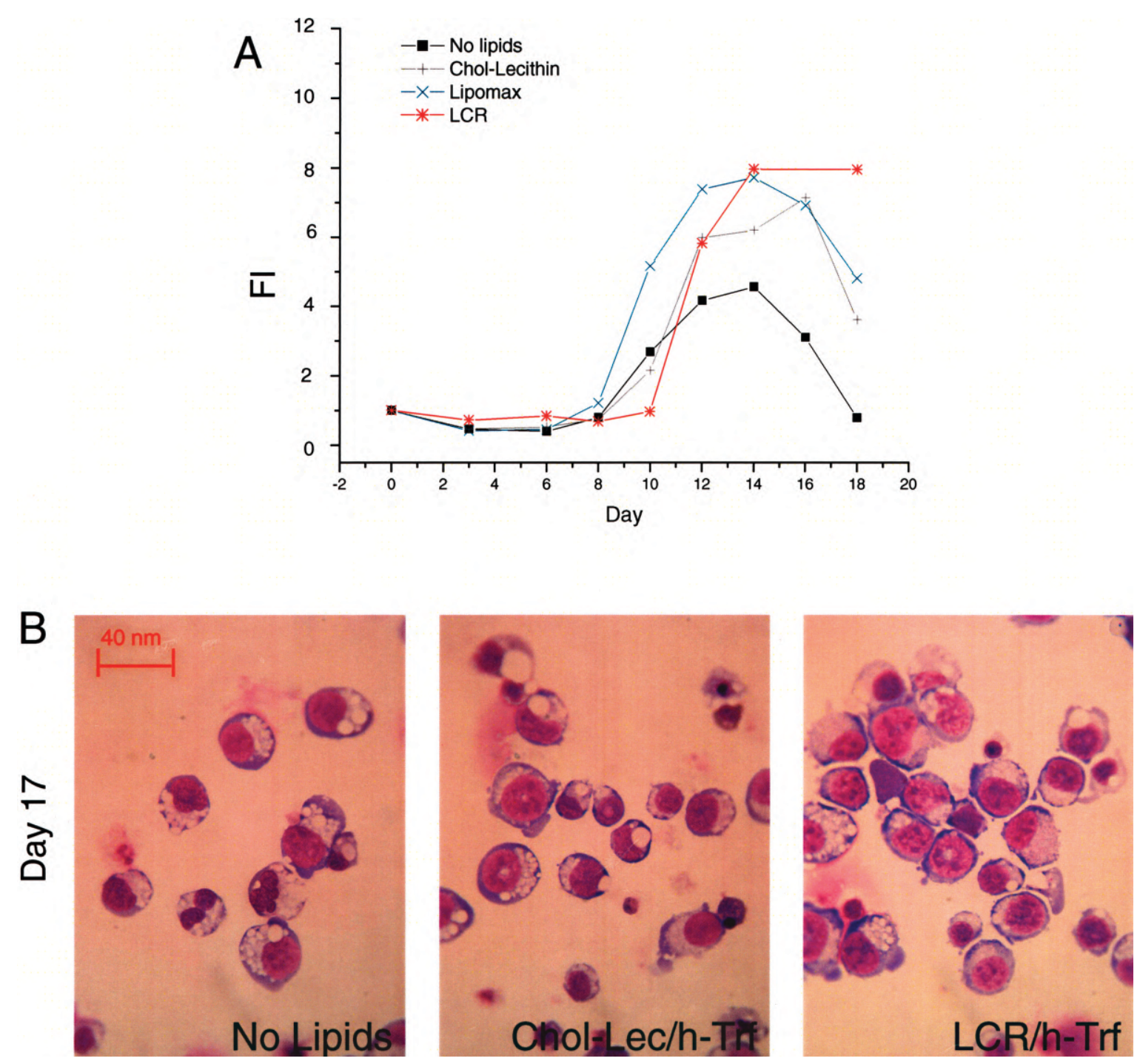

Figure 6. HSA-based liposomes sustain ex vivo amplification of adult erythroblasts as efficiently as commercial lipids of bovine origin. (A) Total number of cells generated in HEMA culture without exogenous addition of lipids, or supplemented with HSAbased liposomes or with two commercial lipid sources of bovine origin, as indicated. A serum-free media based on proteins of bovine origin was used in these experiments. (B) May-Grünwald staining of cytospin preparations of cells from day 17 of the cultures presented above. All the cultures contained iron-saturated human recombinant transferrin (h-Tfr). Results are representative of those obtained in two separate experiments, each with a different donor. Original magnification 40x.

hematopoietic progenitors (data not shown). We hypothesized that the toxicity was due to the presence of low molecular weight additives required to stabilize the albumin in solution to avoid flocculation and devised a strategy to remove these additives by treating the preparation with a double dialysis process (see Materials and Methods). Dialyzed human albumin was then used to prepare the human equivalent of the bovine serum-free medium previously described (32), dubbed HEMA ${ }^{\text {def }}$. A series of experiments was performed to compare the efficacy of HEMA $^{\text {ser }}$ and HEMA ${ }^{\text {def }}$ in supporting ex vivo expansion of EBs from MNCs obtained from cord blood and adult blood (Fig. 7). In cultures of cord blood MNCs, HEMA def sustained generation of erythroid cells in numbers consistently slightly higher (by 1.5 -fold) than those obtained with HEMA $^{\text {ser }}$ media. In cultures initiated with $1 \times 10^{6}$ cord blood MNCs, at day 17, $\sim 300 \times 10^{6}$ and $\sim 500 \times$ $10^{6}$ EBs were obtained in HEMA $^{\text {ser }}$ and HEMA ${ }^{\text {def }}$ medium, respectively.

By flow cytometry, EBs can be divided into three classes of maturation (40): class $1, \mathrm{CD} 36^{\text {high }} \mathrm{CD} 235 \mathrm{a}^{-}$ (CFU-E and proerythroblasts); class 2, CD $36^{\text {high }} \mathrm{CD}$ $235 \mathrm{a}^{\text {high }}$ (basophilic-polychromatic erythroblasts), and class 3, CD $36^{\text {low }} \mathrm{CD} 235 \mathrm{a}^{\text {high }}$ (orthochromatic erythro- 
blasts). In both media, the maturation profile of the cells obtained from cord blood MNCs remained predominantly immature $\left(>60 \%\right.$ of $\mathrm{CD} 366^{+} \mathrm{CD} 235 \mathrm{a}^{\text {low-med }}$ cells $)$ up to day 17 of culture (Fig. 7A). By contrast, in experiments performed with adult blood MNCs, HEMA ${ }^{\text {def }}$ media was clearly superior to HEMA $^{\text {ser }}$ media in sustaining EB amplification (Fig. 7B). Although similar numbers of EBs were generated in the two culture media until day $14\left(\sim 150 \times 10^{6} \mathrm{EBs}\right)$, from day 14 on the number of EBs obtained in $\mathrm{HEMA}^{\text {ser }}$ culture remained constant while that obtained in $\mathrm{HEMA}^{\text {def }}$ media continued to increase up to day 19 , reaching the value of $>750 \times 10^{6}$ cells generated per each original $10^{6} \mathrm{MNC}$ cultured. We believe the superior amplification of adult EBs observed under HEMA ${ }^{\text {def }}$ conditions is likely due to the fact that in these cultures adult EBs remain immature. While the EBs obtained in both cultures were mostly immature at day 7 , in $\mathrm{HEMA}^{\text {ser }}$ they matured by day 9 , in spite of the presence of hormones ( $\left.>50 \% \mathrm{CD}^{-} 6^{-} \mathrm{CD} 235 \mathrm{a}^{\text {high }}\right)$ while remaining immature $\left(>60 \% \mathrm{CD} 36^{+} \mathrm{CD} 235^{- \text {low }}\right)$ until day 19 in HEMA $^{\text {def }}$ (Fig. 6B). Interestingly, the number and morphology of EBs obtained at days 17-19 under HEMA $^{\text {def }}$ conditions from cord blood and adult blood MNC were similar.

These results indicate that, after detoxification, clinical grade human albumin can be used to prepare a cul-
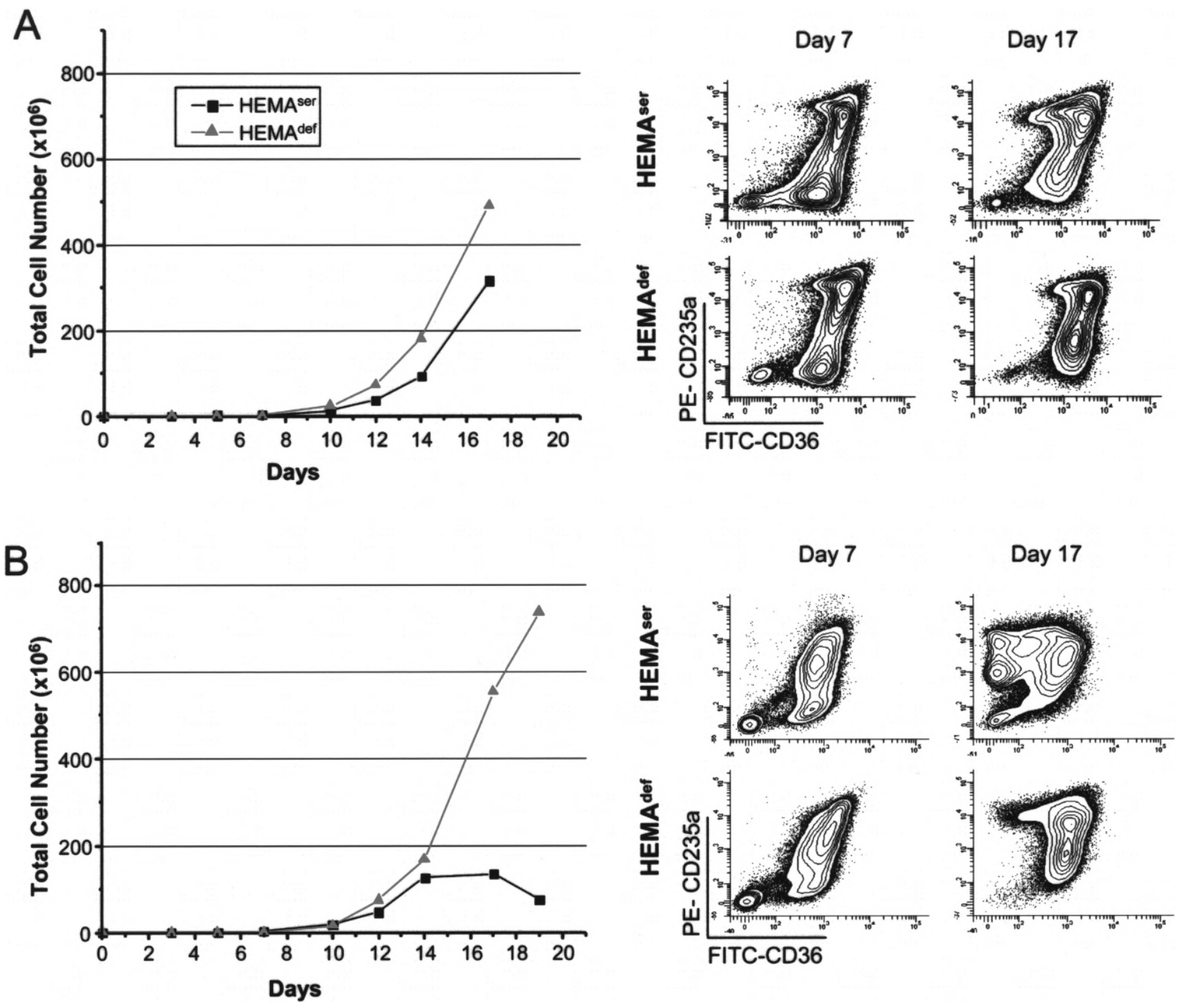

Figure 7. Comparison of the total number and maturation profile of human erythroblasts expanded from cord blood (A) or adult blood (B) MNCs in HEMA ${ }^{\text {ser }}$ or HEMA def media. The maturation profile was defined by FACS analyses on the basis of CD36 and CD235a expression (40). Results are representative of those obtained in three separate cord blood and adult blood experiments, each with a different donor. 
ture medium that generates numbers of human EBs at least similar to those obtained in $\mathrm{HEMA}^{\text {ser }}$ medium. In the case of adult blood MNCs, the use of HEMA ${ }^{\text {def }}$ allowed the generation of numbers of EBs similar to those previously achievable with cord blood MNCs.

\section{DISCUSSION}

The aim of this study was to define the growth factors, hormones, and media required for ex vivo amplification of EBs from adult MNCs. The results obtained confirm SCF, IL-3, and EPO as the growth factor combination that sustains unilineage amplification of EBs. They also confirm that both DXM and ES at a concentration of $10^{-6} \mathrm{M}$ are required for optimal amplifications to occur. Surprisingly, TPO was ineffective in sustaining significant levels of EB generation in cultures containing hormones.

Delayed addition/replacement experiments indicated that DXM and ES exerted their maximal effect at different time points in culture. The presence of DXM was necessary during the first 10 days of culture, when few EBs were recognizable (31). This result confirms microarray studies indicating that the glucocorticoid receptor may promote EB expansion by regulating the expression of a subset of those genes under the control of EPO and SCF (30). In addition to its direct role on EB maturation, DXM may promote EB generation indirectly by blocking the proliferation of $\mathrm{T}$ cells (5), which are particularly numerous at the beginning of the culture, reducing the release of growth inhibitors secreted by these cells. However, during these first 10 days, ES alone was not effective and did not interfere with the effects exerted by DXM.

After day 10, when the cultures were composed mostly of EBs, DXM and/or ES were necessary to generate great numbers of EBs. DXM and ES in combination generated numbers of EBs greater that those generated by DXM alone but inferior to those generated by ES alone. These results indicate that later in culture the two hormones have overlapping but distinctive mechanisms of action. A common target may be represented by GATA1, a transcription factor that exerts a concentration-dependent effect on EB cell fate (38). High levels of GATA1 activity accelerate maturation (56) while low levels induce apoptosis (26). The generation of great numbers of EBs under HEMA conditions is, therefore, dependent on culture conditions that, by maintaining constant levels of GATA1 activity, allow the cells to proliferate. Under HEMA conditions, EPO, by repressing caspase-mediated GATA1 degradation, increases the levels of GATA1 activity and promotes maturation (44). Both DXM and ES reduce GATA1 activity. DXM has been reported to induce rapid GATA1 degradation in MEL cells (8) and in ex vivo-generated human EBs
(49). On the other hand, the activated ES receptor forms a complex with GATA1 that makes this transcription factor transcriptionally inactive (6). It is therefore possible that DXM and ES in combination may decrease too much the level of GATA1 activity, inducing apoptosis and decreasing the number of ex vivo-generated EBs. Alternatively, the greater effects of ES on amplification of EBs may, instead, be related to the fact that ES, in addition to controlling GATA1 activity, might also stimulate telomerase activity in these cells (7).

It has been reported that the levels of telomerase activity increase during EB maturation (43) and that variability in both the length of the telomere (45) and the levels of telomerase expression (2) correlate with the numbers of EBs expanded from $\mathrm{CD}^{+}{ }^{+}$cells obtained from different cord blood units. Therefore, optimal generation of EBs under HEMA conditions may require sequential addition of DXM and ES. However, further experiments are necessary to identify the optimal time at which the culture should be switched from DXM to ES for maximal amplification to occur. These kinetics studies must also evaluate whether genetic polymorphisms at the DXM (11) and ES (7) receptor loci may alter the response of ex vivo-generated EBs to these hormones.

Finally, a humanized media $\left(\mathrm{HEMA}^{\mathrm{def}}\right)$ was identified for ex vivo amplification of EBs from adult MNCs. Under these conditions, adult MNCs generated EBs that remained immature longer and generated greater numbers of EBs, numbers as high as those previously obtained under HEMA $^{\text {ser }}$ conditions only from cord blood MNCs. The reason for the higher numbers of adult EBs obtained under HEMA ${ }^{\text {def }}$ is not known. One of the differences between cord and adult blood MNCs is the activation status of $\mathrm{T}$ cells. Adult $\mathrm{T}$ cells are more mature and react more readily in vitro to antigens than cord blood $\mathrm{T}$ cells (41). It is therefore possible that antigens present on bovine proteins, including albumin, may activate adult T cells in spite of the presence of DXM. It is conceivable then, that replacement of bovine proteins with human protein, in addition to preventing immune-mediated clinical complications, may allow the generation of transfusion products from adult blood donations. Because of their capacity to generate high numbers of EBs ex vivo, cord blood MNCs and CD34+ cells have been up to now considered as the progenitor source of choice for ex vivo generation of erythroid transfusion products $(30,37)$. The observation that adult MNCs generate under HEMA ${ }^{\text {def }}$ conditions numbers of EBs similar to those generated by cord blood MNCs (this manuscript) paves the way to consider discarded MNCs from blood donations as a source of progenitor cells for ex vivo-generated transfusion products.

Using HEMA ${ }^{\text {def }}$ media, MNCs from adult blood donations generated $\mathrm{EB}$ numbers similar to those generated 
by MNCs from cord blood. The identification of other additives (vitamins, cofactors, iron, trace elements, lipids, etc.) that have been described as required for optimal proliferation and that are present in FBS $(15,23,28$, $33,50,51,57)$ may further improve the number and quality of EBs generated from adult MNCs in cultures. We calculated the number of mitotic divisions required to generate $750 \times 10^{6} \mathrm{EBs}$ from the progenitors present in $10^{6}$ adult MNCs in HEMA ${ }^{\text {def }}$ cultures. Given that CD34 ${ }^{+}$ cells represent, on average, $0.1 \%$ of adult blood MNCs and that erythroid progenitors represent in turn $10 \%$ of the $\mathrm{CD}^{2} 4^{+}$cells $(30)$, it can be calculated that HEMA ${ }^{\text {def }}$ cultures were seeded with approximately $10^{2}-10^{3}$ erythroid progenitors. Therefore, the generation of $750 \times$ $10^{6} \mathrm{EBs}$ observed at day 19 in cultures of adult MNCs required that each erythroid progenitor underwent between 19 and 23 mitotic divisions. Because these divisions are still below the theoretical Hayflick's limit of 35 mitotic divisions allocated to somatic cells $(20,21)$, it should be possible, by fine tuning the components of the cultures including the addition schedule of DXM and $\mathrm{ES}$, to further increase the number of EBs that can be generated ex vivo from adult MNCs.

ACKNOWLEDGMENTS: This study was supported by Ministero per la Ricerca Scientifica, Italy (grant No. RBNE0189JJ_003 and RBNE015P72_003) and by the National Cancer Institute (grant No. P01-CA108671) and NY STAR program, USA.

\section{REFERENCES}

1. Baek, E. J.; Kim, H. S.; Kim, S.; Jin, H.; Choi, T. Y.; Kim, H. O. In vitro clinical-grade generation of red blood cells from human umbilical cord blood CD34+ cells. Transfusion 48:2235-2245; 2008.

2. Bartolovic, K.; Balabanov, S.; Berner, B.; Buhring, H. J.; Komor, M.; Becker, S.; Hoelzer, D.; Kanz, L.; Hofmann, W. K.; Brummendorf, T. H. Clonal heterogeneity in growth kinetics of CD34+CD38- human cord blood cells in vitro is correlated with gene expression pattern and telomere length. Stem Cells 23:946-957; 2005.

3. Bauer, A.; Tronche, F.; Wessely, O.; Kellendonk, C.; Reichardt, H. M.; Steinlein, P.; Schutz, G.; Beug, H. The glucocorticoid receptor is required for stress erythropoiesis. Genes Dev. 13:2996-3002; 1999.

4. Bauer, A.; Ulrich, E.; Andersson, M.; Beug, H.; von Lindern, M. Mechanism of transformation by v-ErbA: substitution for steroid hormone receptor function in self renewal induction. Oncogene 15:701-715; 1997.

5. Belgi, G.; Friedmann, P. S. Traditional therapies: Glucocorticoids, azathioprine, methotrexate, hydroxyurea. Clin. Exp. Dermatol. 27:546-554; 2002.

6. Blobel, G. A.; Orkin, S. H. Estrogen-induced apoptosis by inhibition of the erythroid transcription factor GATA-1. Mol. Cell. Biol. 16:1687-1694; 1996.

7. Calado, R. T.; Yewdell, W. T.; Wilkerson, K. L.; Regal, J. A.; Kajigaya, S.; Stratakis, C. A.; Young, N. S. Sex hormones, acting on the TERT gene, increase telomerase activity in human primary hematopoietic cells. Blood 11: 2236-2243; 2009.
8. Chang, T. J.; Scher, B. M.; Waxman, S.; Scher, W. Inhibition of mouse GATA-1 function by the glucocorticoid receptor: Possible mechanism of steroid inhibition of erythroleukemia cell differentiation. Mol. Endocrinol. 7: 528-542; 1993.

9. Costa, E.; Lima, M.; Alves, J. M.; Rocha, S.; RochaPereira, P.; Castro, E.; Miranda, V.; do Sameiro Faria, M.; Loureiro, A.; Quintanilha, A.; Belo, L.; Santos-Silva, A. Inflammation, T-cell phenotype, and inflammatory cytokines in chronic kidney disease patients under hemodialysis and its relationship to resistance to recombinant human erythropoietin therapy. J. Clin. Immunol. 28:268-275; 2008.

10. De Feo, T. M.; Cappellini, M. D.; Fiorelli, G. Effect of estrogens and progesterone on human peripheral erythroid burst-forming unit (BFU-E) growth. Am. J. Hematol. 38: $81-85 ; 1991$.

11. DeRijk, R.; de Kloet, E. R. Corticosteroid receptor genetic polymorphisms and stress responsivity. Endocrine 28: 263-270; 2005.

12. Dorn, I.; Lazar-Karsten, P.; Boie, S.; Ribbat, J.; Hartwig, D.; Driller, B.; Kirchner, H.; Schlenke, P. In vitro proliferation and differentiation of human CD34+ cells from peripheral blood into mature red blood cells with two different cell culture systems. Transfusion 48:1122-1132; 2008.

13. Dukes, P. P.; Goldwasser, E. Inhibition of erythropoiesis by estrogens. Endocrinology 69:21-29; 1961.

14. Edvardsson, L.; Dykes, J.; Olofsson, T. Isolation and characterization of human myeloid progenitor populationsTpoR as discriminator between common myeloid and megakaryocyte/erythroid progenitors. Exp. Hematol. 34: 599-609; 2006.

15. Eliason, J. F.; Odartchenko, N. Colony formation by primitive hemopoietic progenitor cells in serum-free medium Proc. Natl. Acad. Sci. USA 82:775-779; 1985.

16. FDA guidelines for cell therapy. Available at http://www. fda.gov/cber/ind/ind.htm

17. Giarratana, M. C.; Kobari, L.; Lapillonne, H.; Chalmers, D.; Kiger, L.; Cynober, T.; Marden, M. C.; Wajcman, H.; Douay, L. Ex-vivo generation of fully mature human red blood cells from hematopoietic stem cells. Nat. Biotechnol. 23:69-74; 2005.

18. Golde, D. W.; Bersch, N.; Cline, M. J. Potentiation of erythropoiesis in vitro by dexamethasone. J. Clin. Invest. 57:57-62; 1976

19. Gursoy, A.; Dogruk Unal, A.; Ayturk, S.; Karakus, S.; Nur Izol, A.; Bascil Tutuncu, N.; Guvener Demirag, N. Polycythemia as the first manifestation of Cushing's disease. J. Endocrinol. Invest. 29:742-744; 2006.

20. Hayflick, L. The future of ageing. Nature 408:267-269; 2000.

21. Hayflick, L.; Moorhead, P. S. The serial cultivation of human diploid cell strains. Exp. Cell Res. 25:585-621; 1961.

22. Hills, M.; Lucke, K.; Chavez, E. A.; Eaves, C. J.; Lansdorp, P. M. Probing the mitotic history and developmental stage of hematopoietic cells using single telomere length analysis (STELA). Blood 113:5765-5775; 2009.

23. Iscove, N. N.; Guilbert, L. J.; Weyman, C. Complete replacement of serum in primary cultures of erythropoietindependent red cell precursors (CFU-E) by albumin, transferrin, iron, unsaturated fatty acid, lecithin and cholesterol. Exp. Cell Res. 126:121-126; 1980.

24. Kaushansky, K. Lineage-specific hematopoietic growth factors. N. Engl. J. Med. 354:2034-2045; 2006. 
25. Kolbus, A.; Blazquez-Domingo, M.; Carotta, S.; Bakker, W.; Luedemann, S.; von Lindern, M.; Steinlein, P.; Beug, $\mathrm{H}$. Cooperative signaling between cytokine receptors and the glucocorticoid receptor in the expansion of erythroid progenitors: Molecular analysis by expression profiling. Blood 102:3136-3146; 2003.

26. Kuo, Y. Y.; Chang, Z. F. GATA-1 and Gfi-1B interplay to regulate Bcl-xL transcription. Mol. Cell. Biol. 27: 4261-4272; 2007.

27. Leberbauer, C.; Boulme, F.; Unfried, G.; Huber, J.; Beug, H.; Mullner, E. W. Different steroids co-regulate longterm expansion versus terminal differentiation in primary human erythroid progenitors. Blood 105:85-94; 2005.

28. Leimberg, J. M.; Konijn, A. M.; Fibach, E. Developing human erythroid cells grown in transferrin-free medium utilize iron originating from extracellular ferritin. Am. J. Hematol. 73:211-212; 2003.

29. Lu, L.; Pelus, L. M.; Broxmeyer, H. E. Modulation of the expression of HLA-DR (Ia) antigens and the proliferation of human erythroid (BFU-E) and multipotential (CFUGEMM) progenitor cells by prostaglandin E. Exp. Hematol. 12:741-748; 1984.

30. Migliaccio, A. R.; Whitsett, C.; Migliaccio, G. Erythroid cells in vitro: from developmental biology to blood transfusion products. Curr. Opin. Hematol. 16:259-268; 2009.

31. Migliaccio, G.; Di Pietro, R.; di Giacomo, V.; Di Baldassarre, A.; Migliaccio, A. R.; Maccioni, L.; Galanello, R.; Papayannopoulou, T. In vitro mass production of human erythroid cells from the blood of normal donors and of thalassemic patients. Blood Cells Mol. Dis. 28:169-180; 2002.

32. Migliaccio, G.; Migliaccio, A. R. Cloning of human erythroid progenitors (BFU-E) in the absence of fetal bovine serum. Br. J. Haematol. 67:129-133; 1987.

33. Migliaccio, G.; Migliaccio, A. R.; Adamson, J. W. The biology of hematopoietic growth factors: Studies in vitro under serum-deprived conditions. Exp. Hematol. 18:1049$1055 ; 1990$.

34. Migliaccio, G.; Migliaccio, A. R.; Druzin, M. L.; Giardina, P. J.; Zsebo, K. M.; Adamson, J. W. Long-term generation of colony-forming cells in liquid culture of CD34+ cord blood cells in the presence of recombinant human stem cell factor. Blood 79:2620-2627; 1992.

35. Migliaccio, G.; Sanchez, M.; LeBlanc, A.; Masiello, F.; Tirelli, V.; Migliaccio, A. R.; Najfeld, V.; Whitsett, C. Long-term storage does not alter functionality of in vitro generated human erythroblasts: Implications for ex-vivo generated erythroid transfusion products. Transfusion 49: 2668-2679; 2009.

36. Miharada, K.; Hiroyama, T.; Sudo, K.; Nagasawa, T.; Nakamura, Y. Efficient enucleation of erythroblasts differentiated in vitro from hematopoietic stem and progenitor cells. Nat. Biotechnol. 24:1255-1256; 2006.

37. Narla, M. Banking on red blood cells. Nat. Biotechnol. 23:35-36; 2005

38. Orkin, S. H.; Zon, L. I. Hematopoiesis: An evolving paradigm for stem cell biology. Cell 132:631-644; 2008.

39. Panzenbock, B.; Bartunek, P.; Mapara, M. Y.; Zenke, M. Growth and differentiation of human stem cell factor/ erythropoietin-dependent erythroid progenitor cells in vitro. Blood 92:3658-3668; 1998.

40. Papayannopoulou, T.; Abkowitz, J.; D'Andrea, A.; Migliaccio, A. R. Biology of erythtropoiesis, erythroid differentiation and maturation. In: Hoffman, R.; Benz, E. J.; Shat- til, S. J.; Furie, B.; Silberstein, L. E.; McGlave, P.; Heslop, H., eds. Hematology: Basic principles and practice, 5th ed. Philadelphia, PA: Elsevier; 2009:276-294.

41. Peoples, J. D.; Cheung, S.; Nesin, M.; Lin, H.; Tatad, A. M.; Hoang, D.; Perlman, J. M.; Cunningham-Rundles, S. Neonatal cord blood subsets and cytokine response to bacterial antigens. Am. J. Perinatol. 9:647-657; 2009.

42. Piacibello, W.; Sanavio, F.; Garetto, L.; Severino, A.; Bergandi, D.; Ferrario, J.; Fagioli, F.; Berger, M.; Aglietta, M. Extensive amplification and self-renewal of human primitive hematopoietic stem cells from cord blood. Blood 89:2644-2653; 1997.

43. Prade-Houdellier, N.; Frebet, E.; Demur, C.; Gautier, E. F.; Delhommeau, F.; Bennaceur-Griscelli, A. L.; Gaudin, C.; Martinel, V.; Laurent, G.; Mansat-De Mas, V.; Beyne-Rauzy, O. Human telomerase is regulated by erythropoietin and transforming growth factor-beta in human erythroid progenitor cells. Leukemia 21:2304-2310; 2007.

44. Ribeil, J. A.; Zermati, Y.; Vandekerckhove, J.; Cathelin, S.; Kersual, J.; Dussiot, M.; Coulon, S.; Moura, I. C.; Zeuner, A.; Kirkegaard-Sorensen, T.; Varet, B.; Solary, E.; Garrido, C.; Hermine, O. Hsp70 regulates erythropoiesis by preventing caspase-3-mediated cleavage of GATA1. Nature 445:102-105; 2007.

45. Schuller, C. E.; Jankowski, K.; Mackenzie, K. L. Telomere length of cord blood-derived CD34(+) progenitors predicts erythroid proliferative potential. Leukemia 21: 983-991;

46. Selvaggi, T. A.; Walker, R. E.; Fleisher, T. A. Development of antibodies to fetal calf serum with arthus-like reactions in human immunodeficiency virus-infected patients given syngeneic lymphocyte infusions. Blood 89: 776-779; 1997.

47. Shapiro, H. M. Practical flow cytometry, 4th ed. New York: Wiley-Liss; 2003.

48. Singer, J. W.; Adamson, J. W. Steroids and hematopoiesis III. The response of granulocytic and erythroid colonyforming cells to steroids of different classes. Blood 48: 855-864; 1976.

49. Stellacci, E.; Di Noia, A.; Di Baldassarre, A.; Migliaccio, G.; Battistini, A.; Migliaccio, A. R. Interaction between the glucocorticoid and erythropoietin receptors in human erythroid cells. Exp. Hematol. 37:559-572; 2009.

50. Stewart, S.; Zhu, B.; Axelrad, A. A "serum-free" medium for the production of erythropoietic bursts by murine bone marrow cells. Exp. Hematol. 12:309-318; 1984.

51. Takakura, N.; Ogawa, M.; Kodama, H.; Nishikawa, S.; Nishikawa, S. Self-renewal of hematopoietic progenitor cells under defined condition. Leukemia 11(Suppl. 3):460; 1997.

52. Tsiftsoglou, A. S.; Wong, W.; Housman, D. E. Dexamethasone-sensitive and -insensitive responses during in vitro differentiation of Friend erythroleukemia cells. Biochim. Biophys. Acta 759:160-169; 1983.

53. Vicent, G. P.; Ballare, C.; Zaurin, R.; Saragueta, P.; Beato, M. Chromatin remodeling and control of cell proliferation by progestins via cross talk of progesterone receptor with the estrogen receptors and kinase signaling pathways. Ann. NY Acad. Sci. 1089:59-72; 2006.

54. von Lindern, M.; Zauner, W.; Mellitzer, G.; Steinlein, P.; Fritsch, G.; Huber, K.; Lowenberg, B.; Beug, H. The glucocorticoid receptor cooperates with the erythropoietin receptor and c-Kit to enhance and sustain proliferation of erythroid progenitors in vitro. Blood 94:550-559; 1999. 
55. Wessely, O.; Deiner, E. M.; Beug, H.; von Lindern, M. The glucocorticoid receptor is a key regulator of the decision between self-renewal and differentiation in erythroid progenitors. EMBO J. 16:267-280; 1997.

56. Whyatt, D.; Lindeboom, F.; Karis, A.; Ferreira, R.; Milot, E.; Hendriks, R.; de Bruijn, M.; Langeveld, A.; Gribnau, J.; Grosveld, F.; Philipsen, S. An intrinsic but cell-nonautonomous defect in GATA-1-overexpressing mouse erythroid cells. Nature 406:519-524; 2000.
57. Xiaosong, H.; Pierce, L. J.; Cobine, P. A.; Winge, D. R.; Spangrude, G. J. Copper modulates the differentiation of mouse hematopoietic progenitor cells in culture. Cell Transplant. 18:887-897; 2009.

58. Ziegler, B. L.; Muller, R.; Valtieri, M.; Lamping, C. P.; Thomas, C. A.; Gabbianelli, M.; Giesert, C.; Buhring, H. J.; Kanz, L.; Peschle, C. Unicellular-unilineage erythropoietic cultures: Molecular analysis of regulatory gene expression at sibling cell level. Blood 93:3355-3368; 1999. 